\title{
Zusatz zu der Abhandlung: Über die Natur der blutdruckerniedrigenden Substanz in der Sehilddrüse.
}

Von

a. ö. Prof. Dr. Otto v. Fürth und Dr. Carl Sehwarz, Assistenten des physiologischen Institutes der Universität in Wien.

Wie wir zuerst in den Verhandlungen des Kongresses für innere Medizin in Wien ${ }^{1}$ ) Anfang April 1908, sodann in vorstehender Abhandlung mitgeteilt haben, ist von uns der Nachweis erbracht worden, dass die blutdruckerniedrigende Substanz in der Schilddrüse mit dem Cholin identisch ist.

Wie wir einem uns kürzlich zugegangenen Sonderabdrucke aus den Sitzungsberichten der Gesellschaft zur Beförderung der gesamten Naturwissensehaften zu Marburg entnehmen, hat Herr Dr. A. Lohmann am 15. Mai 1908 in der genannten Gesellschaft eine Mitteilung gemacht, aus der hervorgeht, dass er unabhängig von uns zu dem gleichen Resultate gelangt ist.

Da uns bei der Mitte Juli 1908 erfolgten Absendung unserer Abhandlung sowie bei Durchführung der Korrekturen der Befund des Herrn Kollegen Lohmann nicht bekannt war, wir denselben daher nicht erwähnen konnten, sei es uns gestattet, dies nunmehr nachzutragen.

1) O. v. Fürth und C. Schwarz, Über physiologische Wirkungen des Jodothyrins und der Schilddrüsenextrakte nebst Bemerkungen über die Natur der Sekretine. Verhandlungen des XXV. Kongresses für innere Medizin S. 404. Wien 1908. 